\title{
Monitoring the changes to the nutrient composition of fast foods following the introduction of menu labelling in New South Wales, Australia: an observational study
}

\author{
Lyndal Wellard-Cole ${ }^{1, *}$, David Goldsbury ${ }^{2}$, Michelle Havill $^{1}$, Clare Hughes $^{1}$, \\ Wendy L Watson ${ }^{1}$, Elizabeth K Dunford ${ }^{3,4}$ and Kathy Chapman ${ }^{1}$ \\ ${ }^{1}$ Cancer Programs Division, Cancer Council NSW, 153 Dowling Street, Woolloomooloo, NSW 2011 , Australia: \\ ${ }^{2}$ Cancer Research Division, Cancer Council NSW, Woolloomooloo, Australia: ${ }^{3}$ Food Policy Division, The George \\ Institute for Global Health, The University of New South Wales, Sydney, Australia: ${ }^{4}$ Carolina Population Center, \\ The University of North Carolina at Chapel Hill, Chapel Hill, NC, USA
}

Submitted 28 July 2017: Final revision received 2 November 2017: Accepted 9 November 2017: First published online 21 December 2017

\begin{abstract}
Objective: The present study examined the energy (kilojoule) content of Australian fast-food menu items over seven years, before and after introduction of menu board labelling, to determine the impact of the introduction of the legislation.

Design: Analysis of the median energy contents per serving and per $100 \mathrm{~g}$ of fast-food menu items. Change in energy content of menu items across the years surveyed and differences in energy content of standard and limited-time only menu items were analysed.

Setting: Five of Australia's largest fast food chains: Hungry Jack's, KFC, McDonald's, Oporto and Red Rooster.

Subjects: All standard and limited-time only menu items available at each fast-food chain, collected annually for seven years, 2009-2015.

Results: Although some fast-food chains/menu item categories had significant increases in the energy contents of their menus at some time points during the 7-year period, overall there were no significant or systematic decreases in energy following the introduction of menu labelling $(P=0.19$ by $+17 \mathrm{~kJ} / 100 \mathrm{~g}, P=0.83$ by $+8 \mathrm{~kJ} /$ serving). Limited-time only items were significantly higher in median energy content per $100 \mathrm{~g}$ than standard menu items $(+74 \mathrm{~kJ} / 100 \mathrm{~g}, P=0 \cdot 002)$.

Conclusions: While reformulation across the entire Australian fast-food supply has the potential to positively influence population nutrient intake, the introduction of menu labelling legislation in New South Wales, Australia did not lead to reduced energy contents across the five fast-food chains. To encourage widespread reformulation by the fast-food industry and enhance the impact of labelling legislation, the government should work with industry to set targets for reformulation of nutrient content.
\end{abstract}


and voluntary menu labelling has been implemented in the $\mathrm{UK}^{(14)}$. In NSW, menu labelling legislation became enforceable in $2012^{(6)}$. Fast-food chains with twenty or more stores across the state or fifty or more stores nationally are required to display kilojoule information on paper menus and menu boards at the point of sale ${ }^{(6)}$.

To date there have been no studies examining the effect of NSW's menu labelling legislation on the energy content of menu items available at leading fast-food chains. In an aggregated analysis of thirty-seven American sit-down restaurants and fast-food chains, there was a trend towards the availability of lower-energy meals eighteen months after implementation as compared with six months after ${ }^{(7)}$. However, significant decreases in energy, saturated fat and $\mathrm{Na}$ were not seen when fast-food chains were examined independently and there was no change in the energy, saturated fat and $\mathrm{Na}$ contents of menu items ${ }^{(7)}$. A potential explanation for this is that new unhealthy menu items may have been added during the same time period that some nutritional improvements were made to existing menu items $^{(7)}$. More recent US studies on fast-food children's meals ${ }^{(15,16)}$ and chain menu items more broadly ${ }^{(9,10)}$ found very little change in nutrient composition.

To the authors' knowledge, there is no published evidence comparing the energy composition of fast-food menu items both before and after menu labelling implementation. The present study investigated changes to the energy content of fast foods by comparing menu items available at five major Australian fast-food chains over seven years both before and after implementation of menu labelling legislation in NSW.

\section{Methods}

\section{Sampling}

The present study included five of the eight largest fast-food chains in Australia in terms of outlets ${ }^{(17)}$ : Hungry Jack's, KFC, McDonald's, Oporto and Red Rooster. Of the other three chains, Subway was excluded due to its made-to-order style menu, and Domino's Pizza and Pizza Hut were excluded due to their made-to-share style menu.

\section{Procedures}

The study recorded the energy (kilojoule) content of menu items available at a single time point, each year from 2009 to 2015. Best practice suggests that at least three time points prior to the implementation of an initiative are required to enable changes resulting from an initiative to be seen ${ }^{(18)}$. Three time points included (2009, 2010 and 2011) were prior to the announcement of legislation requiring fast-food chains to include kilojoule values on menu boards and four time points (2012, 2013, 2014 and 2015) were after implementation. All time points were in March or April of that year. As the legislation was enforceable as of 1 February 2012, the 2012 data were considered after implementation.

At each time point, the energy contents per $100 \mathrm{~g}$ and per serving of all listed menu items were collected from the Australian website for each of the chains. Chains were contacted to obtain nutrition information for any other menu items available that were not listed on the websites. For the purposes of the present study, standard menu items were those that had been on the menu for more than one consecutive time point and limited-time only menu items were available at only one time point. Where nutrition information was listed in multiple locations, such as on a PDF as well as the webpages, the information with the most recent update date was included. Where no update date appeared, the PDF information was used as the default.

Examples of inconsistent nutrition information available within websites were identified. This included one item with a serving size of $150 \mathrm{~g}$ listed as having more saturated fat per $100 \mathrm{~g}$ than per serving. In this case, the item was excluded.

Menu items were grouped into categories to allow comparisons between similar types of items. Categories were based on previous research ${ }^{(19,20)}$ and included breakfast items, burgers, chicken and seafood items, salads, sandwiches and wraps, sides (e.g. French fries) and desserts. Beverages were excluded from this analysis as many chains serve only pre-bottled beverages, meaning the reformulation of these items is beyond the chain's control.

The publication date of the available nutrition information was recorded and used to determine the information's currency.

\section{Reliability}

To increase reliability, two data collectors were trained using a standard protocol. To ensure data integrity, data were entered by two researchers working independently and cross-checked by a third researcher. Although these steps were taken to improve the reliability of data collection and entry, the accuracy of the data provided by the chains is unknown.

\section{Data analysis}

Data were entered in a Microsoft ${ }^{\circledR}$ Excel 2013 spreadsheet and analysed using the statistical software package SAS version 9.3. $P$ values of $<0.05$ were considered statistically significant.

\section{Before $v$. after menu labelling}

The energy per $100 \mathrm{~g}$ and energy per serving were compared before (years 2009-2011) and after the mandatory energy menu board labelling was implemented (20122015). Bivariable comparisons of energy before and after implementation were carried out using the Wilcoxon 
rank-sum test for all menu items in all years, as well as by chain and menu item category. Multivariable regression modelling was used to determine differences in energy before and after implementation adjusted for chain and menu item category. As menu labelling was legislated in 2012, a sensitivity analysis also checked the results without the 2012 data. Other sensitivity analyses included restricting to standard menu items, restricting to items that were available for the full seven years, excluding discontinued items, and using year as a continuous variable to test for trend rather than a binary before/after implementation categorisation of items.

\section{Standard $\mathrm{v}$. limited-time only menu items}

As fast-food chains use limited-time only menu items to attract new customers ${ }^{(21)}$, analysis was conducted to determine if there were differences between these types of menu items. Bivariable $\chi^{2}$ tests were used to determine if there were differences in the proportion of standard and limited-time only menu items by year, chain and menu item category. The independent effect of each of these factors was assessed using multivariable logistic regression. The energy contents of standard items and limitedtime only items were also compared, both per $100 \mathrm{~g}$ and per serving. A bivariable comparison was carried out using the Wilcoxon rank-sum test and a multivariable general linear model was used to test for any differences after adjusting for year, chain and item category. If a new menu item was added in 2015, then it was not possible to know if it was a limited-time only item or a new standard item, so the 2015 data were excluded from these analyses.

\section{Results}

Across the five fast-food chains, there were 552 unique menu items observed over the study period. The number of items in each category can be seen in Table 1 .

\section{Before v. after menu labelling legislation}

Including all items and years of data and adjusting for menu item category and chain, there was no evidence of a change in energy per serving in menu items available before implementation of menu labelling legislation and those available after, with a non-significant adjusted difference of $+17 \mathrm{~kJ} / 100 \mathrm{~g}(95 \% \mathrm{CI}-9,43 \mathrm{~kJ} / 100 \mathrm{~g}, P=0 \cdot 19$; Table 2). Looking by menu item category and chain, the energy content per $100 \mathrm{~g}$ for burgers was higher after implementation (1040 v. $999 \mathrm{~kJ} / 100 \mathrm{~g}$ before implementation, $P<0.001$ ) and menu items from Oporto had significantly higher energy per $100 \mathrm{~g}$ after implementation (1013 v. $950 \mathrm{~kJ} / 100 \mathrm{~g}$ before implementation, $P<0.001$ ), but there were no other differences by menu item category or chain (see online supplementary material, Tables S1-S4).

After adjusting for menu item category and chain, there was no evidence of a change in energy per serving before or after implementation, with a non-significant adjusted difference of $+8 \mathrm{~kJ} /$ serving (95\% CI $-65,82 \mathrm{~kJ} /$ serving, $P=0.83$; Table 2). Looking by chain there was again an increase for Oporto $(1870 \mathrm{~kJ} / \mathrm{serving}$ after implementation v. $1590 \mathrm{~kJ} /$ serving before implementation, $P<0.001$ ), but there were no other differences by chain or menu item

Table 1 Characteristics of the sample of all standard and limited-time only menu items available at five of Australia's largest fast-food chains, data collected annually for seven years, 2009-2015

\begin{tabular}{|c|c|c|c|c|c|c|}
\hline & \multicolumn{2}{|c|}{ Standard menu items } & \multicolumn{2}{|c|}{ Limited-time only menu items } & \multirow{2}{*}{$\frac{\text { Total menu items }}{n}$} & \multirow[b]{2}{*}{$P$ (difference by category) } \\
\hline & $n$ & $\%$ & $n$ & $\%$ & & \\
\hline \multicolumn{7}{|l|}{ Year } \\
\hline 2009 & 181 & 87 & 26 & 13 & 207 & $<0.001 \dagger$ \\
\hline 2010 & 210 & 84 & 41 & 16 & 251 & \\
\hline 2011 & 232 & 98 & 4 & 2 & 236 & \\
\hline 2012 & 223 & 95 & 12 & 5 & 235 & \\
\hline 2013 & 251 & 88 & 35 & 12 & 286 & \\
\hline 2014 & 246 & 89 & 30 & 11 & 276 & \\
\hline 2015 & 231 & 80 & 56 & 20 & 287 & \\
\hline \multicolumn{7}{|l|}{ Chain } \\
\hline Hungry Jack's & 85 & 65 & 46 & 35 & 131 & 0.18 \\
\hline $\mathrm{KFC}$ & 51 & 68 & 24 & 32 & 75 & \\
\hline McDonald's & 91 & 58 & 67 & 42 & 158 & \\
\hline Oporto & 51 & 63 & 30 & 37 & 81 & \\
\hline Red Rooster & 72 & 67 & 35 & 33 & 107 & \\
\hline \multicolumn{7}{|l|}{ Menu item category } \\
\hline Breakfast & 45 & 70 & 19 & 30 & 64 & $0.003 \dagger$ \\
\hline Burgers & 109 & 64 & 61 & 36 & 170 & \\
\hline Desserts & 42 & 55 & 34 & 45 & 76 & \\
\hline Chicken \& seafood & 40 & 73 & 15 & 27 & 55 & \\
\hline Salads & 24 & 56 & 19 & 44 & 43 & \\
\hline Sides & 40 & 85 & 7 & 15 & 47 & \\
\hline Sandwiches \& wraps & 50 & 52 & 47 & 48 & 97 & \\
\hline
\end{tabular}

*Bivariable $\chi^{2}$ test, excluding 2015 data as we cannot be sure of the standard/limited classification for new items in 2015.

†Denotes significant results, $P<0.05$. 
Table 2 Energy content per $100 \mathrm{~g}$ and per serving for menu items available at five of Australia's largest fast-food chains before (2009-2011) and after (2012-2015) implementation of menu labelling legislation in New South Wales

\begin{tabular}{|c|c|c|c|c|c|c|c|c|c|}
\hline & Years & No. of observations & Median (kJ) & IQR (kJ) & Mean $(\mathrm{kJ})$ & Wilcoxon $P$ & Adjusted diff.* & $95 \% \mathrm{Cl}$ & Adjusted $P$ \\
\hline $\mathrm{kJ} / 100 \mathrm{~g}$ & $\begin{array}{l}2009-2011 \\
2012-2015\end{array}$ & $\begin{array}{r}694 \\
1084\end{array}$ & $\begin{array}{l}970 \\
989\end{array}$ & $\begin{array}{l}820-1110 \\
866-1140\end{array}$ & $\begin{array}{l}942 \\
969\end{array}$ & $0.007 \dagger$ & $17 \mathrm{~kJ} / 100 \mathrm{~g}$ & $-9,43$ & 0.19 \\
\hline $\mathrm{kJ} /$ serving & $\begin{array}{l}2009-2011 \\
2012-2015\end{array}$ & $\begin{array}{r}688 \\
1077\end{array}$ & $\begin{array}{l}1622 \\
1686\end{array}$ & $\begin{array}{l}1140-2203 \\
1180-2243\end{array}$ & $\begin{array}{l}1690 \\
1743\end{array}$ & 0.14 & $8 \mathrm{~kJ} /$ serving & $-65,82$ & 0.83 \\
\hline
\end{tabular}

IQR, interquartile range.

*Difference for items available after implementation minus items available before implementation, adjusted for menu item category and chain.

†Denotes a significant result, $P<0.05$.

Table 3 Differences in energy content of standard and limited-time only menu items available at five of Australia's largest fast-food chains, data collected annually for seven years, 2009-2015

\begin{tabular}{llcccccccc}
\hline & Type of menu item & No. of items & Median $(\mathrm{kJ})$ & IQR $(\mathrm{kJ})$ & Mean $(\mathrm{kJ})$ & Wilcoxon $P$ & Adjusted diff. ${ }^{*}$ & $95 \% \mathrm{Cl}$ & Adjusted $P$ \\
\hline $\mathrm{kJ} / 100 \mathrm{~g}$ & Standard & 1343 & 980 & $855-1123$ & 954 & 0.21 & $74 \mathrm{~kJ} / 100 \mathrm{~g}$ & 27,120 & $0.002 \dagger$ \\
& Limited-time & 148 & 982 & $837-1194$ & 1033 & & & \\
$\mathrm{~kJ} /$ serving & Standard & 1331 & 1660 & $1170-2223$ & 1722 & 0.32 & $3 \mathrm{~kJ} /$ serving & $-130,137$ & 0.96 \\
& Limited-time & 148 & 1639 & $1258-2347$ & 1795 & & & & \\
\hline
\end{tabular}

IQR, interquartile range.

*Difference for limited-time items minus standard items, adjusted for menu item category, chain and year.

†Denotes significant results, $P<0.05$.

category. Comparisons by menu categories within chains cannot be made due to small cell sizes and changes being subject to the addition and removal of items. However, the mean energy per $100 \mathrm{~g}$ and per serving of menu categories within chains can be seen in the online supplementary material, Tables S5 and S6.

\section{Sensitivity analyses}

After adjusting for menu item category and chain, there were no differences between before and after implementation in terms of either energy per $100 \mathrm{~g}$ or energy per serving for any of the following: using only standard menu items, excluding discontinued items, just using items available in all seven years ( $n$ 110), comparing before implementation with 2012 only, or using year as a continuous variable to test for trend (all $P \geq 0 \cdot 10$ for $\mathrm{kJ} / 100 \mathrm{~g}$ and $P \geq 0.60$ for $\mathrm{kJ} /$ serving). The only slight difference found was using standard items and excluding 2012 data (the changeover year), where there was weak evidence of an increase in $\mathrm{kJ}$ per $100 \mathrm{~g}$ after implementation (adjusted difference $+30 \mathrm{~kJ} / 100 \mathrm{~g}, 95 \% \mathrm{CI} 1,59 \mathrm{~kJ} / 100 \mathrm{~g}, P=0 \cdot 04)$. There was no evidence of a reduction in energy content either per $100 \mathrm{~g}$ or per serving for any of these tests (data not shown).

\section{Standard v. limited-time only items}

There were significant differences in the proportion of standard and limited-time only menu items by year and by menu item category (Table 1). After adjusting for menu item category and chain, there was no difference in the proportion of limited-time only items before implementation $v$. after implementation ( $P=0 \cdot 77$; data not shown).

After adjusting simultaneously for category, chain and year, limited-time only items had significantly higher energy content per $100 \mathrm{~g}$ than standard items, with an estimated difference of $74 \mathrm{~kJ} / 100 \mathrm{~g}$ (95\% CI $27,120 \mathrm{~kJ} /$ $100 \mathrm{~g}, P=0.002$; Table 3). There were no differences in energy per serving of standard or limited-time only items ( $P=0.96$; Table 3 ), suggesting that limited-time only menu items were more energy-dense but had smaller serving sizes than standard menu items.

\section{Discussion}

Overall, the present study observed no key changes in fastfood energy content following the introduction of mandatory menu labelling in NSW in 2012. The introduction of energy labelling in Australian fast-food chains has not resulted in reformulation changes which could have a more significant and sustainable impact on energy consumption levels. Our study indicates that the fast-food industry in Australia has not considered a sector-wide approach, or even a chain-wide approach to reformulation, at least not in relation to a reduction in energy content.

The results of our study provide the first Australian evidence on changes (or lack thereof) to fast-food menu item energy content following the implementation of menu labelling. An early study from the USA showed modest energy reductions in fast-food menu items after the implementation of mandatory menu labelling ${ }^{(7)}$; however, that study did not assess energy contents before the implementation of menu labelling. Internationally, the present study is the first to utilise nutrient composition data from both before and after the implementation of menu labelling legislation.

Fast-food chains regularly introduce limited-time only menu items to entice new customers in-store and retain 
existing regular customers ${ }^{(21)}$. In contrast to research conducted in the USA ${ }^{(9)}$, our study found that these items were higher in energy per $100 \mathrm{~g}$ than the standard menu items, although not in energy per serving, indicating smaller serving sizes in limited-time only items. A systematic review of energy density and serving weight showed that people consume a similar weight of foods regardless of the energy density ${ }^{(22)}$. This may be a concern as the serving sizes of the more energy-dense limited-time only items were smaller, which may lead consumers to eat more, which may in turn increase the energy consumed. As consuming foods lower in energy density has been linked to weight loss and maintenance ${ }^{(22,23)}$, reducing the energy density of fast food should be considered a priority by the industry to help address the growing public health burden of obesity and diet-related chronic disease.

Our results suggest that the introduction of menu labelling legislation has not resulted in comprehensive changes in energy content of fast-food menus in Australia. However, an evaluation of the menu labelling legislation in NSW on customer purchasing behaviour showed lower energy content of customers' purchases since the introduction of menu labelling compared with before the implementation ${ }^{(24)}$. Our study shows that chains have not reduced the energy content of menu items, and therefore this reduction in kilojoules purchased may be the effect of menu labelling in improving customer knowledge of energy levels, resulting in healthier choices. To further improve the benefit of reducing kilojoules purchased, reformulation of menu items has the potential to positively impact the energy purchased at fastfood chains. This is an area that the government could pursue to enhance the success of menu labelling.

In 2009, the Australian Government committed to working with the food industry on a range of initiatives ${ }^{(25)}$. The Food and Health Dialogue ${ }^{(26)}$, now replaced by the Food Service Working Group of the Australian Government's Healthy Food Partnership, was formed to improve the food supply via the food-service sector ${ }^{(27)}$. The Food and Health Dialogue sought voluntary commitments from industry to 'encourage appropriate portion size in food service sectors' and 'reduce energy content of food offerings in food service settings', among other activities ${ }^{(27)}$. However, the fast-food industry has not yet released portion size or energy content reformulation targets, nor has it been compelled to do so by the government.

Our research shows no action has been taken by the fastfood industry to reduce energy contents of menu items between 2009 and 2015. This may be because the fast-food industry does not believe there is demand from consumers for lower-energy foods, or the lack of impetus from the government ${ }^{(28)}$; however, there has been no research published to justify this. Reformulation has the potential to improve population dietary intake as it does not require behaviour change by consumers ${ }^{(29)}$. However, while voluntary reformulation effects some change, in the case of salt reduction effectiveness could be increased twentyfold through the implementation of a mandatory approach ${ }^{(30)}$. To improve public health, systematic reformulation of menu items is needed throughout the fast-food sector and a coordinated, government-led approach is recommended ${ }^{(31,32)}$.

The main strengths of our study are the seven years of systematic data collection and the adherence to bestpractice principles for conducting monitoring research on policy initiatives ${ }^{(18)}$. A limitation of the study is the accuracy of the data sources. A number of nutrition information brochures available on chain websites provided different values for the same menu items. In this case, the most recently updated value was used. The online nutrition information for many menu items at two chains did not change over the duration of the study. This may be because the nutrition information was not updated, or the menu items have not changed in six years.

The nutrition information provided by chains online during the study may not have been accurate. For example, Red Rooster updated some of the nutrition information available in HTML format but not the PDF nutrition information available during the study period, with the last stated update on the PDF occurring in 2011. The website for KFC provided multiple nutrition information brochures with different nutrition values for some items. The values listed on the most recently updated information were included in this case. As our study relied solely on electronic nutrition information, the accuracy of the information gathered cannot be guaranteed. A costly solution to this limitation would be to conduct laboratory analysis of menu items over time. However, many chains did provide analysed nutrition information.

As the present study sampled only five fast-food chains in Australia, results cannot be generalised to smaller fastfood chains or other types of outlets covered by the menu labelling legislation, such as ice-creameries, pizza or coffee and snack chains. This research could be repeated in such chains to determine whether the results are mirrored in other types of outlets. Further, as no sales data are available, we could not determine whether the higher-selling items had reductions in energy contents.

\section{Conclusion}

While reformulation across the entire Australian fast-food supply has the potential to positively influence population nutrient intake, our study found that energy levels per $100 \mathrm{~g}$ and per serving across five major Australian fast-food chains did not decrease following the introduction of menu labelling legislation. This suggests there has been no systematic or significant energy reductions made by the fast-food industry. To encourage widespread reformulation by the fast-food industry, the government should work with the industry to set reformulation targets. To ensure the entire fast-food industry responds to such targets, they should be mandatory. 


\section{Supplementary material}

To view supplementary material for this article, please visit https://doi.org/10.1017/S1368980017003706

\section{Acknowledgements}

Financial support: This research received no specific grant from any funding agency in the public, commercial or not-for-profit sectors. E.K.D. was supported by a National Health and Medical Research Council Early Career Fellowship (grant number APP1088673). Conflict of interest: None. Authorship: L.W.-C., W.L.W., C.H. and K.C. formulated the research question and designed the study. L.W.-C., M.H. and W.L.W. collected and entered the data. L.W.-C., M.H. and D.G. conducted the data analysis. L.W.-C. prepared the manuscript. All authors contributed to the review of the manuscript and preparation for submission. Ethics of buman subject participation: Not applicable.

\section{References}

1. Australian Bureau of Statistics (2013) Australian Health Survey: Updated Results, 2011-12. Canberra: ABS.

2. Prentice A (2006) The emerging epidemic of obesity in developing countries. Int J Epidemiol 35, 93-99.

3. Australian Bureau of Statistics (2011) 6530.0 - Household Expenditure Survey, Australia: Detailed Expenditure Items, 2009-10. http://www.abs.gov.au/AUSSTATS/abs@. nsf/DetailsPage/6530.02009-10?OpenDocument (accessed August 2015).

4. Burton S, Creyer E, Kees J et al. (2006) Attacking the obesity epidemic: the potential health benefits of providing nutrition information in restaurants. Am J Public Health 96, 1669-1675.

5. Dumanovsky T, Huang CY, Nonas CA et al. (2011) Changes in energy content of lunchtime purchases from fast food restaurants after introduction of calorie labelling: cross sectional customer surveys. BMJ 343, d4464.

6. New South Wales Government (2014) Food Act 2003 No 43. Part 8 Regulation of Food Businesses. Division 4 Requirements Relating to Display of Nutritional Information for Food. https://legislation.nsw.gov.au/\#/view/act/2003/43/ part8/div4 (accessed November 2017).

7. Bruemmer B, Krieger J, Saelens BE et al. (2012) Energy, saturated fat, and sodium were lower in entrees at chain restaurants at 18 months compared with 6 months following the implementation of mandatory menu labeling regulation in King County, Washington. J Acad Nutr Diet 112, 1169-1176.

8. Saelens BE, Chan NL, Krieger J et al. (2012) Nutritionlabeling regulation impacts on restaurant environments. $\mathrm{Am}$ J Prev Med 43, 505-511.

9. Bleich SN, Wolfson JA \& Jarlenski MP (2016) Calorie changes in large chain restaurants. Am J Prev Med 50, e1-e8.

10. Jarlenski MP, Wolfson JA \& Bleich SN (2016) Macronutrient composition of menu offerings in fast food restaurants in the US. Am J Prev Med 51, e91-e97.

11. ACT Parliamentary Counsel (2015) Display of nutritional information for food under Food Act 2001. http:// www.legislation.act.gov.au/a/2001-66/current/pdf/2001-66. pdf (accessed December 2017).
12. Government of South Australia (2012) South Australia Food Variation Regulations 2012 under the Food Act 2001. http://www.legislation.sa.gov.au/LZ/V/R/2012/FOOD\%20 VARIATION\%20REGULATIONS\%202012_7/2012.7.UN.PDF (accessed March 2013).

13. US Government (2010) The Patient Protection and Affordable Care Act. http://www.gpo.gov/fdsys/pkg/PLAW-111 publ148/html/PLAW-111publ148.htm (accessed November 2014).

14. UK Government, Department of Health (2012) Public Health Responsibility Deal: Food pledges. http://www. responsibilitydeal.dh.gov.uk/pledges/ (accessed November 2014).

15. Moran AJ, Block JP, Goshev SG et al. (2017) Trends in nutrient content of children's menu items in US chain restaurants. Am J Prev Med 52, 284-291.

16. Deierlein AL, Peat K \& Luz C (2015) Comparison of the nutrient content of children's menu items at US restaurant chains, 2010-2014. Nutr J 14, 80.

17. IBISWorld (2015) IBISWorld Industry Report G4111. Supermarkets and Grocery Stores in Australia. Melbourne: IBISWorld.

18. Eccles M, Grimshaw J, Campbell M et al. (2003) Research designs for studies evaluating the effectiveness of change and improvement strategies. Qual Saf Health Care 12, 47-52.

19. Dunford E, Webster J, Barzi F et al. (2010) Nutrient content of products served by leading Australian fast food chains. Appetite 55, 484-489.

20. O'Donnell S, Hoerr SL, Mendoza JA et al. (2008) Nutrient quality of fast food kids' meals. Am J Clin Nutr 88, 1388-1395.

21. Glanz K, Resnicow K, Seymour J et al. (2007) How major restaurant chains plan their menus - the role of profit, demand, and health. Am J Prev Med 32, 383-385.

22. Pérez-Escamilla R, Obbagy JE, Altman JM et al. (2012) Dietary energy density and body weight in adults and children: a systematic review. J Acad Nutr Diet 112, 671-684.

23. World Cancer Research Fund \& American Institute for Cancer Research (2007) Food, Nutrition, Physical Activity, and the Prevention of Cancer: A Global Perspective. Washington, DC: AICR.

24. NSW Food Authority (2013) Evaluation of Kilojoule Menu Labelling. Sydney: NSW Food Authority.

25. Australian Government, Department of Health (2012) Food and Health Dialogue Newsletter, 5th ed. http://www.food healthdialogue.gov.au/internet/foodandhealth/publishing. nsf/Content/newsletter-5 (accessed April 2016).

26. Australian Government, Department of Health (2016) Food and Health Dialogue. http://www.health.gov.au/internet/ main/publishing.nsf/Content/fhd (accessed December 2017).

27. Healthy Food Partnership (2017) Work Plan for Food Service Working Group. Canberra: Healthy Food Partnership.

28. Elliott T, Trevena H, Sacks G et al. (2014) A systematic interim assessment of the Australian Government's Food and Health Dialogue. Med J Aust 200, 92-95.

29. Schwartz MB \& Brownell KD (2007) Actions necessary to prevent childhood obesity: creating the climate for change. J Law Med Ethics 35, 78-89.

30. Cobiac LJ, Vos T \& Veerman JL (2010) Cost-effectiveness of interventions to reduce dietary salt intake. Heart 96, 1920-1925.

31. Reeve B \& Magnusson R (2015) Food reformulation and the (neo)-liberal state: new strategies for strengthening voluntary salt reduction programs in the UK and USA. Public Health 129, 1061-1073.

32. Collins M, Mason H, O'Flaherty M et al. (2014) An economic evaluation of salt reduction policies to reduce coronary heart disease in England: a policy modeling study. Value Health 17, 517-524. 